1 Universidade Federal da Bahia (UFBA), Instituto de Ciências da Saúde

(ICS), Departamento de Fonoaudiologia e Instituto de Saúde Coletiva (ISC),

Programa de PósGraduação em Saúde Coletiva - Salvador (BA) Brasil.

vladimir.arce@ufba.br

2 Universidade Federal da Bahia (UFBA), Instituto de Humanidades, Artes e Ciências (IHAC) e Instituto de Saúde Coletiva (ISC), Programa de Pós-

Graduação em Saúde

Coletiva - Salvador (BA)

Brasil.

carment@ufba.br

\section{Práticas de saúde e modelo de atenção no âmbito do Núcleo de Apoio à Saúde da Família em Salvador (BA)}

\author{
Health practices and healthcare model in the scope of the Family \\ Health Support Center in Salvador (BA)
}

Vladimir Andrei Rodrigues Arce', Carmen Fontes Teixeira ${ }^{\mathbf{2}}$

RESUMO Buscou-se analisar a organização tecnológica do processo de trabalho dos profissionais que atuam no Núcleo de Apoio à Saúde da Família (Nasf) em Salvador (BA), de modo a verificar a possível contribuição desta proposta à mudança do modelo de atenção à saúde. Trata-se de pesquisa qualitativa, do tipo estudo de caso. Verificou-se que os profissionais buscam realizar um cuidado ampliado aos usuários, porém, prevalece uma organização do processo de trabalho fundamentada na atenção clínica individualizada, com algumas ações de cunho preventivo, coadunando os modelos da Clínica Ampliada e Sanitarista. Faz-se necessária a apropriação de instrumentos de trabalho que permitam a compreensão das necessidades sociais da população, com vistas à integralidade da atenção.

PALAVRAS-ChAVe Saúde da família. Atenção Primária à Saúde. Prática de saúde pública. Política de saúde. Serviços de saúde.

ABSTRACT The aim of this article was to analyze the technological organization of the work process of the professionals working in the Family Health Suppport Center (Nasf) in Salvador $(B A)$, in order to verify the possible contribution of this proposal to the change in the health attention model. This is a qualitative research, of case study type. It was verified that professionals seek to carry out an extended care to the users, however, the individualized clinical attention prevails in the work process organization, with some preventive actions, corroborating the Broadened and Sanitary Clinic models. It is necessary the appropriation of labor instruments that allow the understanding of the population social needs, with a view to the integrality of the healthcare.

KEYWORDS Family health. Primary Health Care. Public health practice. Health policy. Health services. 


\section{Introdução}

A implantação dos Núcleos de Apoio à Saúde da Família (Nasf) representa uma inovação organizacional no âmbito da Atenção Primária à Saúde (APS), no Sistema Único de Saúde (SUS), e tem por objetivo contribuir para a integralidade da atenção à saúde da população coberta pela Estratégia Saúde da Família (ESF). Deste modo, espera-se que as equipes multiprofissionais que atuam nestes núcleos organizem seus processos de trabalho a partir da realidade socioeconômica e epidemiológica dos territórios, não enfocando apenas as ações clínicas individuais, mas também a articulação dos serviços de saúde e demais equipamentos sociais, identificando prioridades, prevenindo riscos e promovendo saúde (BRASIL, 2012, 2009).

Dado o pouco tempo de implantação dos Nasf, poucas são as evidências científicas acerca dos efeitos destes núcleos sobre o perfil de oferta da rede básica. Entretanto, não é raro perceber a reprodução de práticas profissionais reduzidas a seus aspectos técnicos e descontextualizadas, geralmente orientadas pelo conhecimento específico das especialidades, sobretudo relacionadas a ações de tratamento ou reabilitação (ARAÚJo; GALIMBERTTI, 2013; COSTA ET AL., 2013; LEITE; ANDRADE; BOSI, 2013; RODRIGUES; BOSI, 2014; SOUSA; OLIVEIRA; COSTA, 2015). Logo, identifica-se uma tendência ao privilégio de práticas clínicas, em detrimento das ações de promoção da saúde e prevenção de riscos e agravos, que continuariam, portanto, subalternas ao modelo médico hegemônico (TEIXEIRA; VILASBÔAS, 2014).

Considerando que a mudança desse modelo implica na reorientação das práticas profissionais, é importante analisar as práticas de saúde desenvolvidas pelos profissionais dos Nasf, buscando entender as potencialidades e os limites das mesmas para o apoio à reorientação do modelo de atenção à saúde, em suas várias dimensões - gerencial, organizativa e técnico-assistencial (TEIXEIRA, 2006). Ressalta-se que as práticas de saúde devem ser compreendidas como processo de trabalho, não podendo ser reduzidas a seus aspectos técnicos, mas como conjuntos estruturados de práticas sociais, históricas (MENDES-GONÇALVES, 1988, 1992), que resultam da articulação dos diferentes componentes, quais sejam: o objeto, os instrumentos ou meios utilizados no trabalho, a finalidade das atividades, a necessidade que orienta o trabalho e as relações sociais estabelecidas neste processo (MENDES-GONÇALVES, 1992), através das quais seus agentes articulam sua prática à totalidade social (PEDUZZI, 2003).

Nessa perspectiva, o presente trabalho tem como objetivo analisar a organização tecnológica do processo de trabalho dos profissionais que atuam no Nasf em Salvador (BA), de modo a verificar a possível contribuição desta proposta à mudança do modelo de atenção à saúde.

\section{Metodologia}

Trata-se de pesquisa qualitativa do tipo estudo de caso (YIN, 2005) sobre o processo de trabalho dos profissionais dos Nasf de Salvador (BA). Em 2015, o município dispunha de 11 equipes Nasf, sendo duas delas registradas no Cadastro Nacional de Estabelecimentos de Saúde (CNES) há menos de um ano da realização da pesquisa, que dão apoio a aproximadamente 100 Equipes de Saúde da Família (EqSF). Compõem estas equipes profissionais de educação física, fisioterapia, nutrição, psicologia, serviço social e terapia ocupacional.

A definição dos sujeitos da pesquisa foi feita com a utilização da técnica Snow Ball, sendo consideradas as indicações da área técnica responsável pelos Nasf na Secretaria Municipal de Saúde (SMS) do município, de docentes da Universidade Federal da Bahia que desenvolveram estágios com estas equipes, e dos próprios profissionais inicialmente indicados. Utilizou-se como critérios de inclusão: a) profissionais considerados referências em suas equipes por se destacarem 
no processo de implantação e desenvolvimento do Nasf, de forma geral; b) profissionais que atuavam há aproximadamente um ano na mesma equipe Nasf; e c) profissionais de equipes cadastradas há pelo menos um ano no CNES. Estes dois últimos critérios buscaram favorecer a escolha de profissionais capazes de reconhecer as principais características do cotidiano do trabalho das equipes. Buscou-se garantir ao menos um representante de cada categoria profissional que compunha o Nasf em Salvador (BA), e ao menos um profissional de cada equipe, o que permitiu a seleção e inclusão de 12 profissionais de 9 equipes Nasf.

Para a produção dos dados, foram realizadas entrevistas semiestruturadas com os sujeitos, e também foi elaborado um diário de campo para o registro de situações e impressões subjetivas relevantes para a pesquisa. O material obtido foi submetido à análise de conteúdo (BAUER, 2002), de modo a contemplar a caracterização das 'práticas de saúde/processo de trabalho dos profissionais do NASF', especificamente seus elementos estruturais - 'objeto, atividades, instrumentos de trabalho, finalidades, necessidades e relações sociais' -, de acordo com o referencial teórico adotado (MENDES-GONÇALVES, 1992, 1988). A partir destes dados, foi possível realizar uma análise comparativa entre as práticas identificadas com os modelos hegemônicos e as propostas alternativas descritas na literatura (quadro 1), de modo a verificar se está ocorrendo, na realidade estudada, um 'processo de mudança ou conservação do modelo de atenção à saúde' no âmbito do Nasf.

Quadro 1. Características dos modelos hegemônicos e das propostas de mudança na organização da atenção à saúde no SUS

\begin{tabular}{|c|c|c|}
\hline & Modelos de atenção & Principais características \\
\hline \multirow[t]{2}{*}{ Hegemônicos } & $\begin{array}{l}\text { Modelo médico- } \\
\text {-assistencial hospita- } \\
\text { locêntrico }\end{array}$ & $\begin{array}{l}\text { Fundamenta-se na clínica e na medicina científica, centrando-se na figura do } \\
\text { médico; Atuação com foco na doença e nos doentes, na perspectiva individual; } \\
\text { Hospital e rede de serviços privados como principais lócus de organização; } \\
\text { Instrumentos de trabalho centrados na tecnologia médica. }\end{array}$ \\
\hline & Sanitarista & $\begin{array}{l}\text { Subalterno ao modelo médico-assistencial hospitalocêntrico; } \\
\text { Foco nas campanhas sanitárias e na elaboração e implantação dos programas } \\
\text { especiais verticais de controle de doenças e outros agravos, o que influencia o } \\
\text { surgimento de sistemas de vigilância em saúde; } \\
\text { Os sujeitos das práticas são os sanitaristas; } \\
\text { O objeto central da atuação está nos modelos de transmissão das doenças, } \\
\text { com especial foco nos fatores de risco; } \\
\text { Instrumentos de trabalho são centrados na tecnologia sanitária, a exemplo de } \\
\text { ações de educação em saúde, controle de vetores e imunização. }\end{array}$ \\
\hline \multirow[t]{2}{*}{$\begin{array}{l}\text { Propostas } \\
\text { alternativas }\end{array}$} & Distritos sanitários & $\begin{array}{l}\text { Estratégia de reorganização dos serviços na perspectiva sistêmica; } \\
\text { Ênfase na delimitação dos territórios/áreas de abrangência da rede de serviços } \\
\text { e na articulação dos diversos níveis de complexidade; } \\
\text { Foco no perfil da demanda e nas necessidades de saúde da população; } \\
\text { Articula instrumentos advindos da geografia crítica, da epidemiologia e do } \\
\text { enfoque situacional de planejamento. }\end{array}$ \\
\hline & $\begin{array}{l}\text { Oferta organizada/ } \\
\text { ações programáticas } \\
\text { de saúde }\end{array}$ & $\begin{array}{l}\text { Foco na reorganização do processo de trabalho e do processo de produção de } \\
\text { serviços desenvolvido em uma unidade de saúde, visando superar a lógica da } \\
\text { demanda espontânea; } \\
\text { A programação em saúde busca articular diversas ofertas vinculadas ao aten- } \\
\text { dimento das necessidades e dos problemas específicos da população, incorpo- } \\
\text { rando uma lógica epidemiológica e social. }\end{array}$ \\
\hline
\end{tabular}




\begin{tabular}{|c|c|c|}
\hline \multicolumn{3}{|c|}{ Quadro 1. (cont.) } \\
\hline \multirow[t]{4}{*}{$\begin{array}{l}\text { Propostas } \\
\text { alternativas }\end{array}$} & Vigilância da Saúde & $\begin{array}{l}\text { Incorpora experiências de distritos sanitários e o debate da promoção da saúde e da } \\
\text { determinação social do processo saúde-doença em coletividades humanas; } \\
\text { Integralidade da atenção, articulando práticas de controle dos determinantes, } \\
\text { riscos e agravos à saúde, por meio de práticas de promoção, prevenção e assis- } \\
\text { tência; } \\
\text { O objeto do trabalho se refere aos problemas de saúde; } \\
\text { Tem como instrumentos de trabalho as abordagens participativas de planeja- } \\
\text { mento, sobretudo aquelas com enfoque estratégico-situacional, além de tecno- } \\
\text { logias médicas, sanitárias e de comunicação social; } \\
\text { Apoia-se na ação intersetorial, utilizando o conceito epidemiológico de risco e } \\
\text { intervindo sob a forma de operações. }\end{array}$ \\
\hline & Acolhimento & $\begin{array}{l}\text { Preocupação com a gestão e a organização do trabalho no âmbito das unidades } \\
\text { de saúde; } \\
\text { Foco no acolhimento e no estabelecimento de vínculos entre profissionais e } \\
\text { população; } \\
\text { Base do modelo em defesa da vida; } \\
\text { Foco na humanização e na melhoria da qualidade da atenção }\end{array}$ \\
\hline & Clínica Ampliada & $\begin{array}{l}\text { Impulsionada pela proposta do acolhimento; } \\
\text { Constituída nos pressupostos das equipes de referência, no apoio matricial e na } \\
\text { elaboração de Projeto Terapêutico Singular (PTS), visando ajudar trabalhadores } \\
\text { e usuários a lidarem com a complexidade dos sujeitos e a multiplicidade dos } \\
\text { problemas de saúde. }\end{array}$ \\
\hline & Saúde da Família & $\begin{array}{l}\text { Articulação de elementos provindos de vários movimentos ideológicos, incorporan- } \\
\text { do propostas alternativas, tais como a Vigilância da Saúde e o acolhimento; } \\
\text { Torna-se estratégia de mudança do modelo de atenção à saúde no SUS, } \\
\text { buscando-se cobertura universal e reorganização do processo de trabalho em } \\
\text { saúde da atenção básica, além de buscar promover mudanças nos demais } \\
\text { níveis de atenção do sistema. }\end{array}$ \\
\hline
\end{tabular}

Fonte: Elaborado a partir de Teixeira e Vilasbôas (2014).

Esta pesquisa foi aprovada pelo Comitê de Ética em Pesquisa, do Hospital Universitário Professor Edgar Santos da Universidade Federal da Bahia (Hupes/UFBA), sob o número 473.854/2013, seguindo as diretrizes da Resolução $\mathrm{n}^{\circ} 466$, de 2012, do Conselho Nacional de Saúde.

\section{Resultados}

A idade média dos sujeitos da pesquisa, a maioria mulheres, era de 32 anos, variando de 26 a 39, com tempo médio de formação igual a 8,3 anos, variando entre 4 e 16 anos. A média de tempo em que trabalhavam em suas equipes foi equivalente a dois anos. Do total, $58 \%$ se formaram em universidades públicas e $75 \%$ não fizeram estágio na ESF durante a graduação. Ainda, $58 \%$ possuíam ou estavam cursando pós-graduação em área correlata ao campo da saúde coletiva, sendo que apenas um profissional possuía mestrado na área e 16\% tinham especialização voltada para atuação clínica.

\section{Atividades e instrumentos de traba- Iho no Nasf}

As 'atividades clínicas voltadas para os usuários' foram as mais citadas, observando-se o predomínio de atendimentos clínicos de curta duração, compartilhados principalmente com outros profissionais do Nasf e, em menor expressão, com profissionais das EqSF, além de atendimentos em grupo e visitas domiciliares. Constatou-se, porém, uma grande dificuldade dos profissionais para dar continuidade aos processos terapêuticos iniciados, por não possuírem 
estrutura física adequada nem agenda específica de atendimento, além da baixa adesão das EqSF a essas atividades.

Também é significativa a realização de 'atividades educativas de prevenção', sobretudo em grupos conduzidos pelas EqSF (controle do tabagismo, hiperdia, grupo de idosos e gestantes), bem como em grupos organizados pelo próprio Nasf (grupo de atividades físicas, controle da obesidade e saúde mental) ou atividades pontuais (salas de espera, feiras de saúde e campanhas sanitárias promovidas pela SMS). Estas são orientadas principalmente pela agenda programática dos serviços e pelo perfil do profissional.

Também são desenvolvidas 'atividades de apoio às EqSF', prioritariamente em reuniões para discussão de casos, capacitação em relação a temáticas específicas e organização do processo de trabalho das EqSF. Nota-se, principalmente, neste contexto, o propósito da instrumentalização dos profissionais em relação às questões técnicas do cuidado.

As 'atividades de planejamento, gestão, capacitação e organização do trabalho da equipe Nasf' foram relatadas por oito entrevistados, sendo que estas atividades acontecem, em sua maioria, durante as reuniões semanais da equipe Nasf para planejamento das ações a serem propostas às EqSF, embora também sirvam, de maneira assistemática e menos expressiva, para confeccionar material informativo, bem como sistematizar informações em saúde. Ademais, são realizadas discussões de casos entre os profissionais do Nasf, que se capacitam não apenas em relação a determinados agravos à saúde, mas, também, acerca do próprio trabalho. Um entrevistado afirmou que tais atividades representam um espaço também de avaliação permanente do trabalho. Foram citadas, ainda, reuniões com áreas técnicas da SMS, reuniões gerais das unidades de saúde onde estão lotados e atividades pontuais de apoio aos gestores locais.

As 'atividades de articulação da rede de saúde/território' foram as menos citadas pelos entrevistados, sendo a principal delas a articulação com escolas, por meio do desenvolvimento de ações preventivas junto ao Programa Saúde na Escola (PSE). Também foram relatadas visitas a serviços de saúde especializados para encaminhamento de usuários e, de maneira bastante incipiente, visitas a demais equipamentos sociais ou contato com lideranças comunitárias.

Em relação aos 'instrumentos de trabalho' utilizados nas atividades do Nasf, a maioria dos entrevistados referiu-se a instrumentos imateriais, a exemplo da capacidade comunicacional criativa e proativa que o profissional deve ter para desenvolver seu trabalho em equipe, de maneira flexível, comprometida e participativa, valorizando o diálogo e a criação de vínculos, sendo capaz de resolver conflitos e de lidar com imprevistos de forma planejada. Referem também a importância da ampliação do olhar sobre o cuidado à população, inserindo novas abordagens e metodologias de trabalho na relação com os usuários, como a terapia comunitária e práticas integrativas, sobretudo voltadas para o acolhimento humanizado e para a valorização da subjetividade. A capacidade crítica de articulação política foi apontada como necessária ao trabalho por apenas dois entrevistados.

Os instrumentos materiais referidos incluem o uso de formulários e prontuários para o registro dos Planejamentos Terapêuticos Singulares (PTS), livros-ata para o registro das atividades coletivas e a comunicação entre profissionais, e lista de critérios para a definição de atendimentos individuais, bem como materiais necessários à operacionalização de atividades educativas com os usuários (audiovisuais e de escritório).

\section{Objetos e necessidades}

Em relação aos 'objetos', é possível verificar maior enfoque das ações sobre o indivíduo e a doença, ainda que de forma ampliada, ou seja, considerando a subjetividade e o contexto familiar e social em que os usuários vivem. Em menor escala, foi possível 
perceber que o trabalho das EqSF também se configura como um dos objetos de trabalho do Nasf, na medida em que ampliá-lo, qualificá-lo e transformá-lo são propósitos assumidos por seis entrevistados. As 'condições de vida da população’ também são consideradas objetos sobre os quais atuam os profissionais, porém, de forma assistemática e pontual. E, por fim, os 'modos de adoecimento' e 'fatores de risco' são apontados por metade dos entrevistados como focos do trabalho do Nasf, abordados a partir de práticas de prevenção de doenças voltadas para a mudança de comportamento da população.

Já em relação às 'necessidades que orientam o trabalho dos profissionais', os entrevistados fazem referência às condições de vida e trabalho da população, o que inclui questões de acesso a moradia, educação de qualidade, lazer, saneamento e emprego, entre outros, ou seja, necessidades sociais determinantes da saúde. Sete dos entrevistados apontam a necessidade de maior acesso da população a profissionais e serviços de saúde, considerando a elevada demanda por atendimentos especializados, que são pouco estruturados na rede de atenção à saúde do município.

\section{Finalidades}

A finalidade do trabalho do Nasf, segundo os entrevistados, é a "transformação das práticas de saúde dos profissionais das EqSF, de forma a provocar mudanças no modelo de atenção". Neste sentido, consideram que o modo como as EqSF organizam seu trabalho não está de acordo com o propósito central da ESF, por ser focado no atendimento ambulatorial individual, com pouca ação interdisciplinar, sendo as ações coletivas de prevenção e promoção da saúde negligenciadas no cotidiano, ou resumidas à execução das ações previstas em programas verticais.

\section{Relações sociais}

As relações estabelecidas no cotidiano do trabalho do Nasf foram agrupadas em quatro eixos. As 'relações com a gestão' prevaleceram no discurso de todos os entrevistados, com grande referência à situação precária em que se encontra a ESF no município, que é percebida pelos profissionais como burocratizada, desestruturada e negligenciada pelo poder público. Para os entrevistados, esta situação interfere nas condições de trabalho, que são agravadas pela falta de uma política de gestão do trabalho e pela insuficiência de uma rede de atenção à saúde para dar suporte à APS. Já o vínculo de trabalho estável e a existência de uma técnica de referência para o Nasf no município que compreende e apoia, em alguma medida, o trabalho dos profissionais, ainda que com pouca governabilidade no âmbito da gestão, foram considerados fatores positivos.

As 'relações com as EqSF' também foram bastante citadas pelos entrevistados. Todos referiram que vem ocorrendo uma melhora neste aspecto desde que os Nasf foram reestruturados com a chegada dos novos servidores, embora conflitos e tensionamentos sigam existindo, pois há uma tendência à desresponsabilização da EqSF pelo andamento dos casos, quando acionam o Nasf, o que ocorre frequentemente de maneira improvisada. Para os entrevistados, as EqSF são instigadas a mudarem suas práticas centradas no atendimento ambulatorial, o que incomoda e afasta algumas equipes. Neste contexto, dois entrevistados demonstraram o incômodo de se sentirem dependentes das equipes, uma vez que o trabalho do Nasf demanda necessariamente uma articulação com a EqSF.

De forma geral, os profissionais do Nasf se sentem subutilizados, tendo que, a todo momento, convencer as equipes a buscá-los para construírem ações em conjunto, o que gera desânimo e, até mesmo, sofrimento. Todos os núcleos buscaram construir vínculos com as EqSF, a partir do acolhimento ou mesmo do atendimento ambulatorial a casos que eram encaminhados ou demandados, de forma a abrir possibilidades de diálogo entre 
as equipes, o que acabou dando maior centralidade à prática voltada para o indivíduo e para os agravos/doenças. Percebe-se maior vinculação aos enfermeiros e aos Agentes Comunitários de Saúde (ACS), e menor aos médicos, sobretudo por estes rodiziarem bastante no serviço, ocasionando menor disponibilidade para a prática em conjunto com o Nasf. As relações desiguais de poder também foram citadas por quatro entrevistados, sendo que a desvalorização do ACS ou as disputas entre profissões que compõem as EqSF foram citadas como complicadores do estabelecimento de uma melhor articulação de trabalho com o Nasf.

As 'relações estabelecidas entre os profissionais do Nasf', por sua vez, foram consideradas positivas pela maioria dos entrevistados, havendo o estabelecimento de parcerias interdisciplinares de forma efetiva, horizontal e coesa em diferentes atividades. O perfil dos profissionais foi considerado um potencial para o desenvolvimento da proposta, uma vez que a grande maioria apresenta disponibilidade para o trabalho, ainda que a formação específica para isto seja incipiente. A relação efetiva entre as diferentes equipes Nasf do município possibilitou a criação de um movimento político a favor da capacitação para o trabalho, o que levou à constituição da comissão de educação permanente do Nasf, propiciando a articulação entre as equipes e a socialização de ideias, ações e dúvidas, processo que avançou para o questionamento da situação de precarização da saúde em todo o município, com intensa participação no movimento de greve dos servidores municipais da saúde ocorrida em 2015.

Por fim, quanto às 'relações do Nasf com a população', além de terem sido as menos citadas, apresentaram variações entre as equipes. Metade dos entrevistados afirmou que "a população não compreende o que é o Nasf", e frequentemente "cobra abertura de agenda para atendimentos ambulatoriais". Apenas dois entrevistados afirmaram que há uma boa inserção do Nasf na comunidade.

\section{Discussão}

Considerando-se que as práticas de saúde não devem se limitar às características técnicas, nota-se um movimento dos profissionais do Nasf para reforçar a ampliação destas práticas no sentido da construção de um cuidado ampliado aos usuários dos diferentes territórios estudados. Entretanto, este movimento não demonstra ser suficiente para afirmar uma nova socialidade no âmbito da ESF baseada na efetiva integralidade da atenção e na atuação sobre os problemas de saúde, uma vez que o olhar sobre o indivíduo tende a prevalecer em relação ao olhar sobre o coletivo.

Essa questão tem seu início na constatação do perfil dos profissionais que participaram da pesquisa, pois embora tenham, em geral, pouco tempo de formados, a maioria não vivenciou a ESF durante a graduação, evidenciando que a formação generalista, integrada ao sistema de saúde e interdisciplinar, ainda segue sendo um desafio para o SUS (VENDRUSCOLO; PRADO; KLEBA, 2014). De toda forma, a busca individual por qualificação em cursos de pós-graduação em Saúde Coletiva demonstra a disponibilidade destes profissionais para este trabalho em especial.

Em relação às 'práticas de saúde/processo de trabalho dos profissionais do Nasf', o predomínio de atividades de cunho clínico-assistencial evidencia o peso que é dado à clínica, aos diferentes agravos/doenças e aos sujeitos adoecidos. Esta questão também pode ser percebida nas ações técnico-pedagógicas junto às EqSF, quando há uma centralidade no conhecimento específico para a instrumentalização dos profissionais em relação às questões técnicas do cuidado, o que tem limitado o desenvolvimento de outras práticas, tais como a de promoção da saúde e a de vigilância da saúde, como demonstrado em outros estudos (ARAÚJO; GALIMBERTTI, 2013; COSTA ET AL., 2013; RODRIGUES; BOSI, 2014) e evidenciado, também, nesta pesquisa.

O principal objeto de trabalho do Nasf em Salvador (BA), que se refere aos indivíduos e às doenças/agravos à saúde contextualizados 
nas relações familiares e sociais, evidencia um cuidado clínico que perpassa, sobretudo, pela valorização do sujeito, da singularidade e das relações imbricadas em seu processo de adoecimento, corroborando Cunha (2005), e pelo compartilhamento do conhecimento e pelo estabelecimento de vínculos, de forma que os usuários possam lidar melhor com suas questões, ou mesmo resolvê-las, reforçando a perspectiva de cuidado humanizado e ampliado, conforme defende Ayres (2004).

A constatação de que há um predomínio de instrumentos imateriais sobre os materiais reforça a perspectiva de construção dessa nova abordagem clínica na ESF. Entretanto, há pouca referência ao uso de novas tecnologias imateriais de planejamento, de intervenções clínicas ou mesmo de comunicação social, ou seja, o trabalho aparenta estar sendo desenvolvido de forma intuitiva, baseado na relação subjetiva e nas características pessoais dos profissionais, o que pode limitar o alcance das práticas desenvolvidas, devendo ser objeto de capacitação para a qualificação do trabalho.

Ao se constatar que o Nasf também possui, como objeto de trabalho, os modos de adoecimento e fatores de risco, reconhece-se a busca por uma ampliação da prática, para além da clínica, o que ocorre por meio de práticas educativas, que demandam os principais instrumentos materiais usados no trabalho. Entretanto, a pouca realização de práticas de promoção da saúde evidencia a fragilidade da articulação com demais equipamentos sociais do território, ou mesmo com as lideranças comunitárias, reforçando o lugar de marginalidade da promoção da saúde na APS, sendo esta uma das limitações da ESF para dar conta de reorientar o modelo de atenção à saúde (TEIXEIRA, 2006).

Essa questão é ainda mais notória quando a capacidade crítica de articulação política do profissional no âmbito da saúde é apontada como necessária por poucos profissionais, bem como quando as condições de vida e trabalho da população, que deveriam ser objeto central do trabalho na ESF, configuram-se como objetos do trabalho de forma assistemática e pontual, ainda que sejam percebidas como necessidades da população. Desta forma, verifica-se que as práticas de prevenção ora desenvolvidas tendem a responder principalmente às propostas verticais de educação em saúde, por vezes independentes da análise de situação de saúde do território, o que também foi observado por Costa et al. (2013). Com isto, de forma geral, reforça-se uma perspectiva tradicional de educação em saúde, centrada no conteúdo, ainda que algumas propostas com caráter emancipatório possam ser percebidas em menor grau.

Isso evidencia uma possível contradição do trabalho, já que, embora os profissionais afirmem perceber a magnitude das necessidades sociais que incidem sobre a saúde da população, não demonstram enfrentá-las sistematicamente no âmbito do território, ocasionando a construção de um olhar ampliado para os indivíduos e agravos à saúde, sem que, necessariamente, os determinantes deste processo e os impactos sobre o coletivo sejam concretizados como objetos do trabalho. Reforça esta ideia a constatação de que parte das necessidades da população identificada pelos profissionais se refere ao acesso a tratamentos ou serviços de referência em outros níveis de atenção, o que evidencia a falta de uma rede estruturada de atenção à saúde para dar suporte à grande demanda da população, sendo a articulação desta rede um papel desempenhado de maneira precária pelos profissionais, ainda que esta coordenação seja uma função da APS, conforme apontam Rodrigues et al. (2014). Esta fragilidade da rede interfere diretamente no trabalho do Nasf, na medida em que exerce pressão para uma ênfase maior na dimensão clínico-assistencial.

$O$ fato de a atuação das EqSF também ser identificada como um dos objetos de trabalho do Nasf demonstra o quão estratégico este núcleo pode ser nas propostas de qualificação da ESF, podendo ser um instrumento mobilizador e provocador de mudanças, uma vez que sua característica pressupõe a inserção 
de novas rotinas no cotidiano das EqSF, ainda que encontre resistências, como foi observado neste estudo. Neste sentido, verifica-se que o trabalho no Nasf, enquanto política pública, possui uma dimensão gerencial importante, sendo que práticas de planejamento e gestão do próprio trabalho são recorrentes e necessárias para a operacionalização do apoio às equipes, o que inclui ações voltadas para a capacitação.

Essa dimensão demonstra ser essencial para a definição e a articulação de todas as demais atividades realizadas pela equipe. Entretanto, faz-se necessário que as práticas de planejamento e gestão sejam mais bem estruturadas no âmbito do Nasf, como também apontam Araújo e Galimbertti (2013), devendo ser parte essencial do processo de trabalho, e não apenas vivenciadas de forma improvisada ou intuitiva, o que deverá favorecer a democratização e a redução da alienação no trabalho, de forma a mobilizar as vontades de diferentes atores, conforme aponta Paim (2006), de forma estratégica e participativa, o que é frágil na realidade observada.

Diante desse contexto, é interessante notar que há uma preocupação dos profissionais do Nasf em promover mudanças nas práticas das EqSF, que são entendidas como fragmentadas e centradas no modelo médico hegemônico. Este dado demonstra que os profissionais do Nasf avaliam que as EqSF não cumprem com seu papel de ampliação da APS, o que frequentemente ocasiona tensionamentos entre as equipes, ainda que diversas parcerias ocorram, evidenciando a complexidade que marca as relações sociais estabelecidas na realidade estudada.

A começar pela relação com a gestão, há um entendimento comum a todos os entrevistados de que o Nasf ocupa um lugar de não prioridade no âmbito da gestão municipal, por não haver uma política clara de incentivo ao seu pleno funcionamento. Esta realidade se estende à ESF como um todo, que conta com baixa cobertura populacional e pouco investimento político e financeiro, o que tem afetado também a disponibilidade e a motivação destes profissionais para o trabalho, corroborando a ideia de que o maior desafio para o SUS é o político (PAIM ET AL., 2011), dificultando o papel de reorientação do modelo de atenção à saúde que se espera da ESF.

Os problemas na relação com as EqSF persistem, em menor grau, ainda hoje em algumas realidades locais, e estão diretamente ligados ao fato de o Nasf não aceitar suprir a demanda de atendimentos clínicos ambulatoriais solicitada pelas EqSF, o que também foi constatado por Lancman et al. (2013). As concessões feitas de modo a lidar com os tensionamentos iniciais e construir algum vínculo com as EqSF acabaram por tornar esta prática central no trabalho, o que precisa ser revisto. Além disto, o fato de a construção destas práticas clínicas ocorrerem sem a efetiva adesão das EqSF, e também sem a disponibilidade de recursos materiais específicos para intervenções de ordem clínica, ainda que diferenciada, sinaliza o risco de estarem sendo construídas práticas simplificadas de cuidado, que são reforçadas pelas dificuldades apontadas pelos profissionais em dar seguimento aos casos abordados, o que poderia reforçar uma perspectiva reducionista de extensão de cobertura de serviços básicos de APS, como caracteriza Paim (2012), o que precisa ser mais bem analisado.

De toda forma, o fato de o Nasf não ceder à lógica do encaminhamento e atendimento ambulatorial tradicional evidencia que há, ainda que de maneira incipiente, uma diferenciação em relação às propostas de trabalho dessas equipes, nas quais o Nasf ocupa e sustenta o lugar de crítica e de mudança, reforçando a potencialidade desta proposta para a qualificação da ESF no município. Porém, percebe-se que há uma relação desigual entre essas equipes, sendo o Nasf colocado em um lugar de subordinação, tendo que, a todo momento, convencê-las a aderirem ao trabalho, o que gera desgaste e desânimo em alguns profissionais.

$\mathrm{O}$ fato de as relações profissionais serem mais profícuas com enfermeiros e ACS, e 
menos com médicos, demonstra que ainda há um distanciamento do médico em relação às propostas de trabalho em equipe na APS, também observado por Costa et al. (2013), tornado ainda mais difícil pelas situações de alta rotatividade deste profissional nos serviços. Este é um importante desafio a ser enfrentado, uma vez que o médico segue sendo o elemento central do processo assistencial em saúde no nível institucional (PIRES, 2000). Entretanto, a recente renovação de muitos profissionais das EqSF tem sido considerada uma potencialidade do momento atual da ESF em Salvador (BA), onde novos arranjos e pactuações se tornaram possíveis devido a uma maior motivação para o trabalho destes novos profissionais.

A boa relação estabelecida entre os profissionais que atuam no Nasf evidencia a potencialidade desta proposta para a efetivação da interdisciplinaridade, o que representa um avanço para o trabalho na APS. Entretanto, faz-se necessário ampliar esta questão em direção às EqSF, o que foi observado também por Gonçalves et al. (2015), considerando-se o risco de haver um processo de autonomização da equipe, que pode gerar a fragmentação do trabalho e um maior distanciamento entre as equipes. Ainda sobre este aspecto, cabe registrar que o movimento de articulação dos profissionais de todas as equipes de Salvador (BA) tem permitido não apenas as trocas de experiências de trabalho como também a construção de um sujeito coletivo, que vem desenvolvendo ações que explicitam e defendem os interesses coletivos, o que também tem possibilitado a construção de um processo de trabalho relativamente homogêneo entre as equipes, ainda que com algumas diferenças, ao contrário do que foi observado por Leite, Nascimento e Oliveira (2014).

A fragilidade da relação do Nasf com a população, por sua vez, acaba limitando a prática de ações individuais, ou grupais, de forma pontual, enfraquecendo a possibilidade de esta relação constituir uma estratégia política de melhoria da atenção à saúde, o que evidencia os desafios que devem ser enfrentados pelos profissionais, gestores e pela própria população, que dizem respeito, sobretudo, a um maior envolvimento dos usuários na construção, na efetivação e na avaliação das políticas de APS.

Diante desses achados, verifica-se a existência de um processo contraditório na realidade estudada, uma vez que as práticas de saúde dos profissionais do Nasf tendem a concretizar a perspectiva da Clínica Ampliada, ao mesmo tempo em que reproduzem atividades características do modelo Sanitarista. Ou seja, ao mesmo tempo em que buscam superar as práticas clínicas biomédicas das EqSF, buscam extrapolar o âmbito da clínica por meio de práticas centradas na prevenção dos problemas que são objetos de programas prioritários, porém ainda majoritariamente de forma pouco integrada à análise da situação de saúde dos territórios. Deste modo, avançam, por um lado, na implementação de uma proposta de mudança, ao mesmo tempo em que reforçam a conservação do modelo de atenção hegemônico.

Essa situação é fortemente influenciada pelo contexto técnico e político no qual o Nasf está inserido, enquanto parte da política de atenção básica, mas sua gênese também reside na dificuldade de articular práticas profissionais historicamente voltadas para a clínica e para o conhecimento especializado. Ressalta-se que a fragilidade do processo de construção da integralidade da atenção faz com que propostas cunhadas sob o olhar epidemiológico - como é o caso da Vigilância da Saúde (Visau) - sejam pouco fomentadas, o que é evidenciado na incipiência de ações de vigilância e de promoção da saúde no âmbito do Nasf. Neste sentido, faz-se necessário que os propósitos do trabalho do Nasf sejam mais bem definidos e assumidos pela gestão, uma vez que a Visau seja o modelo de atenção assumido pelo município como orientador da reorganização da APS e do SUS, o que pode gerar convergências e contradições que precisam ser analisadas em novas pesquisas. 
Assim, a situação do Nasf em Salvador (BA) evidencia as lacunas que devem ser enfrentadas nos campos da formação e do trabalho em saúde, que vão desde a qualificação técnica para o trabalho cotidiano até o aprimoramento do processo de gestão da proposta. Entretanto, é principalmente a capacidade de ação política dos sujeitos envolvidos na construção cotidiana destes núcleos que deve ser estrategicamente fortalecida, sobretudo em contextos atuais de fragilização das políticas públicas em geral, e da saúde, em particular, o que torna permanentemente necessário o debate sobre as práticas de saúde e os modelos de atenção.

\section{Considerações finais}

Os achados deste estudo evidenciam que o processo de trabalho dos profissionais do Nasf ainda está em construção e amadurecimento, havendo características por vezes contraditórias no que diz respeito à sua capacidade de contribuir para a reorientação do modelo de atenção à saúde. Assim, reconhece-se a potencialidade do Nasf em provocar mudanças no processo de trabalho das EqSF, mas ainda se faz necessário que os processos de trabalho do próprio Nasf sejam mais bem estruturados, com definições de finalidades, atividades e instrumentos de trabalho coerentes com um objeto ampliado, para além do indivíduo e da doença, o que deve ocorrer de forma atrelada à ESF em geral.

De todo modo, a presença de uma proposta tensionadora do modelo hegemônico, que persiste mesmo na ESF, representa uma janela de oportunidade a ser cada vez mais explorada, de forma que a sensibilidade para as questões sociais demonstrada no cotidiano do trabalho se traduza em ações planejadas e executadas por esses profissionais na perspectiva da integralidade da atenção. Esta questão requer, além de políticas de capacitação da força de trabalho que ora atua nesses núcleos, investimento político e financeiro na proposta, além de maior compromisso das instituições formadoras com a mudança no desenvolvimento dos profissionais de saúde, para que não se corra o risco de que esta proposta se torne a expressão de uma contrarreforma no cerne da APS, sobretudo em contextos onde a ESF esteja fragilizada, como é o caso da realidade estudada. 


\section{Referências}

ARAÚJO, E. M. D.; GALIMBERTTI, P. A. A colaboração interprofissional na estratégia saúde da família. Psicologia \& Sociedade, Rio de Janeiro, v. 25, n. 2, p. 461468, 2013. Disponível em: <http://www.scielo.br/pdf/ psoc/v25n2/23.pdf>. Acesso em: 2 jan. 2017.

AYRES, J. R. C. M. O cuidado, os modos de ser (do) humano e as práticas de saúde. Saúde e Sociedade, São Paulo, v. 13, n. 3, p. 16-29. 2004. Disponível em: <http:// www.scielo.br/scielo.php?script=sci_arttext\&pid $=$ S0104-12902004000300003 $>$. Acesso em: 2 jan. 2017.

BAUER, M. W. Análise de conteúdo clássica: uma revisão. In: BAUER, M. W.; GASKELL, G. Pesquisa Qualitativa com texto, imagem e som: um manual prático. Petrópolis: Vozes, 2002. p. 189-217.

BRASIL. Ministério da Saúde. Diretrizes do NASF: Núcleo de Apoio à Saúde da Família. Brasília, DF: Ministério da Saúde, 2009.

Ministério da Saúde. Política Nacional de

Atenção Básica. Brasília, DF: Ministério da Saúde, 2012.

COSTA, L. S. et al. A prática do fonoaudiólogo nos Núcleos de Apoio à Saúde da Família em municípios paraibanos. CoDAS, São Paulo, v. 25, n. 4, p. 381-387, 2013. Disponível em: <http://www.scielo.br/scielo. php?pid=S2317-17822013000400014\&script=sci abstract\&tlng=pt $>$. Acesso em: 2 jan. 2017.

CUNHA, G. T. A construção da Clínica Ampliada na Atenção Básica. São Paulo: Hucitec, 2005.

GONCALVES, R. M. A. et al. Estudo do trabalho em Núcleos de Apoio à Saúde da Família (NASF), São Paulo, Brasil. Revista Brasileira de Saúde Ocupacional, São Paulo, v. 40, n. 131, p. 59-74. 2015. Disponível em: $<$ http://www.scielo.br/pdf/rbso/v40n131/0303-7657-rbso-40-131-59.pdf >. Acesso em: 2 fev. 2017.

LANCMAN, S. et al. Estudo do trabalho e do trabalhar no Núcleo de Apoio à Saúde da Família. Revista de Saúde Pública, São Paulo, v. 47, n. 5, p. 968-975, 2013. Disponível em: <http://www.scielo.br/pdf/rsp/ v47n5/0034-8910-rsp-47-05-0968.pdf>. Acesso em: 2 fev. 2017.

LEITE, D. C.; ANDRADE, A. B.; BOSI, M. L. M. A inserção da Psicologia nos Núcleos de Apoio à Saúde da Família. Physis, Rio de Janeiro, v. 23, n. 4, p. 1167-87, 2013. Disponível em: <http:// www.scielo.br/scielo.php?script=sci_arttext\&pid =S0103-73312013000400008 >. Acesso em: 2 fev. 2017.

LEITE, D. F.; NASCIMENTO, D. D. G.; OLIVEIRA, M. A. C. Qualidade de vida no trabalho de profissionais do NASF no município de São Paulo. Physis, Rio de Janeiro, v. 24, n. 2, p. 507-525, 2014. Disponível em: <http://www.scielo.br/scielo.php?pid=S0103$-73312014000200507 \&$ script $=$ sci_abstract\&tlng $=p t>$. Acesso em: 2 fev. 2017.

MENDES-GONÇALVES, R. B. Práticas de saúde: processos de trabalho e necessidades. São Paulo: CEFOR, 1992.

Práticas de saúde e tecnologia: contribuição para a reflexão teórica. Brasília, DF: OPS, 1988.

PAIM, J. Atenção Primária à Saúde: uma receita para todas as estações? Saúde em Debate, Rio de Janeiro, v. 36, n. 94, p. 343-347, jul./set. 2012. Disponível em: $<$ http://www.scielo.br/scielo.php?script=sci_arttext\&pi $\mathrm{d}=$ S0103-11042012000300004>. Acesso em: 2 fev. 2017.

Planejamento em saúde para não especialistas. In: CAMPOS, G. W. S. et al. (Org.). Tratado de saúde coletiva. São Paulo: Hucitec, 2006. p. 767-782.

PAIM, J. et al. O sistema de saúde brasileiro: história, avanços e desafios. The Lancet, [S. 1.], v. 377, n. 9779, p. 1-31, 2011.

PEDUZZI, M. Mudanças tecnológicas e seu impacto no processo de trabalho em saúde. Trabalho, Educação e Saúde, Rio de Janeiro, v. 1, n. 1, p. 75-91. 2003. Disponível em: <http://www.scielo.br/pdf/tes/vlnl/07. pdf $>$. Acesso em: 2 fev. 2017. 
PIRES, D. Reestruturação produtiva e consequências para o trabalho em saúde. Revista Brasileira de Enfermagem, Brasília, DF, v. 53, n. 2, p. 251-263, 2000. Disponível em: <http://www.scielo.br/scielo. php?pid=S0034-71672000000200010\&script $=$ sci_ abstract\&tlng=es >. Acesso em: 2 fev. 2017.

RODRIGUES, D. C. M.; BOSI, M. L. M. O lugar do nutricionista nos Núcleos de Apoio à Saúde da Família. Revista de Nutrição, Campinas, v. 27, n. 6, p. 735-746, 2014. Disponível em: <http://www.scielo.br/scielo. php?pid=S1415-52732014000600735\&script $=$ sci abstract\&tlng=pt>. Acesso em: 2 fev. 2017.

RODRIGUES, L. B. B. et al. A atenção primária à saúde na coordenação das redes de atenção: uma revisão integrativa. Ciência \& Saúde Coletiva, Rio de Janeiro, v. 19, n. 2, p. 343-352, 2014. Disponível em: <http://www.scielo.br/scielo.php?pid=S1413$-81232014000200343 \&$ script $=$ sci_abstract $\&$ tlng $=$ pt $>$. Acesso em: 2 fev. 2017.

SOUSA, D.; OLIVEIRA, I. F.; COSTA, A. L. F. Entre o especialismo e o apoio: psicólogos no Núcleo de Apoio à Saúde da Família. Psicologia USP, São Paulo, v. 26, n. 3, p. 474-83, 2015. Disponível em: <http://www.scielo.br/scielo.php?pid=S0103$-65642015000300474 \&$ script $=$ sci_abstract $\&$ tlng $=$ pt $>$. Acesso em: 2 fev. 2017.
TEIXEIRA, C. F. Promoção da saúde e SUS; um diálogo permanente. In: TEIXEIRA, C. F.; SOLLA, J. P. Modelo de atenção à saúde: vigilância e saúde da família. Salvador: EDUFBA, 2006.

TEIXEIRA, C. F.; VILASBÔAS, A. L. Q. Modelos de Atenção à Saúde no SUS: mudança ou conservação? In: PAIM, J. S.; ALMEIDA-FILHO, N. Saúde Coletiva: Teoria e Prática. Rio de Janeiro: Medbook, 2014. p. 287-301.

VENDRUSCOLO, C.; PRADO, M. L.; KLEBA, M. E. Formação de recursos humanos em saúde no Brasil: uma revisão integrativa. Educação em Revista, Belo Horizonte, v. 30, n. 1, p. 215-44. 2014. Disponível em: <http://www.scielo.br/scielo.php?pid=S0102$-46982014000100009 \&$ script $=$ sci_abstract $\&$ tlng $=p t>$. Acesso em: 2 fev. 2017.

YIN, R. K. Estudo de caso: planejamento e métodos. Porto Alegre: Bookman, 2005.

Recebido para publicação em março de 2017 Versão final em agosto de 2017

Conflito de interesses: inexistente Suporte financeiro: apoio financeiro para transcrição das entrevistas: Observatório de Análise Política em Saúde (OAPS/ ISC/UFBA) - Chamada MCTI / CNPq / CT-Saúde / MS / SCTIE/ Decit n 41/2013 